\title{
Editorial
}

\section{COVID - 19: A Reflection}

\author{
Shankar Pathiyil Ravi', Kshitiz Upadhyay Dhungel2 \\ Editors, JMCJMS
}

${ }^{1}$ Faculty, International Centre for Education, International Medical University, Kuala Lumpur, Malaysia

2Professor, Editor in chief, JMCJMS

\section{ABSTRACT}

Corona virus disease-19 has caused widespread morbidity and mortality and significant economic disruption. Most individuals including me did not expect the pandemic to affect human life for so long. There have been multiple waves in some countries. In most persons the disease is mild and these individuals can spread the virus. About $15 \%$ of those infected may need hospital treatment and intensive care. Traditional measures like lockdowns, travel restrictions and quarantine have been used in the absence of an effective treatment or vaccine. A climate of fear has been created by some studies and media reports. Traditional daily activities have been affected and some may no longer be possible. Schools and colleges have shut down and shifting education online. There have been organizational failures and instances of profiteering during the pandemic. Many of the measures implemented have required individuals to provide personal data and accept restrictions on their freedom. The tourism and travel industry has been hit hard and millions of individuals may slip back into poverty. The information about the pandemic is rapidly evolving and is often confusing.

Key words: COVID-19, economic, education, impact, poverty, reflections, travel

\section{INTRODUCTION}

The Corona virus disease-19 (COVID-19) pandemic caused by the severe acute respiratory syndrome corona virus-2 (SARS CoV-2) has been one of the most disruptive of my lifetime causing substantial morbidity and mortality and serious economic consequences. As of $23^{\text {rd }}$ August 2020, the disease has infected 23.1 million individuals and 0.8 million have died. ${ }^{1}$ The pandemic has changed the way we live, work and communicate.

My initial impressions: When the disease was first reported from Wuhan, China in late December 2019 and early January 2020 I did not expect it to 'shut down' the world for such a prolonged period of time. We had serious epidemics before like the pneumonic plague, SARS, MERS and Ebola. These were serious but could be localized and did not spread to become a pandemic. This pandemic has been often compared to the Spanish flu outbreak of the last century. When I visited the Government Medical College in Thrissur, Kerala, India during early February,students from Wuhan, China were under treatment at the hospital. The disease appeared to be under control. The pandemic however, has an unfortunate tendency to come in repeated waves and just when you think things are under control, the disease returns.

What makes COVID-19 so disruptive? The virus causes mild disease in most people and 
in many there are no symptoms. So, persons infected with the virus are able to travel and interact with healthy people and spread the virus. The virus is more infective than the influenza virus. The major problem is that in about 10 to $15 \%$ of those infected the virus can cause a more severe disease and even result in death. It can cause pneumonia, breathing difficulty and hypoxia and many of these individuals will require intensive care and ventilatory support. These individuals can strain health systems especially if their numbers increase. Older individuals, especially those over 70 years and persons with coexisting conditions like hypertension, diabetes mellitus and respiratory diseases are especially vulnerable. The world has aged significantly and many individuals have chronic diseases. The world is also more interconnected today than ever before.

We do not have an effective antiviral drug against the virus yet, though many medicines have shown promise. We have long neglected infectious diseases and our success against major infections during the last century has led to a sense of complacency. A virus spreading by the respiratory route and more contagious than the flu is always dangerous and disruptive.

Shutting down the world and the new normal: In the absence of effective treatments and vaccines public health experts and governments globally took recourse to old measures like quarantine, shutdowns, and sealing of borders. These measures took a serious toll on the economy and on mental health. Access to healthcare may have been compromised. Treatment of non-COVID conditions has become difficult. The free movement of people globally which has characterized our generation suddenly ceased. Movements of goods is also facing increasing barriers. Global air travel came to a grinding halt. Surface transport slowed down to a trickle. Country, regional and district barriers which had slowly been dismantled over the last two hundred years came firmlyback in place. The disease provided a new flashpoint for old historical grievances and rivalries. In the big cities of India for over two months you were confined to your apartment. Traveling anywhere required moving through a maze of red tape.

A climate of fear: Most articles and scientific publications painted a picture of doom and gloom. Millions will be dead, hospitals overwhelmed and people may be dying on the streets. Luckily even in the worst hit countries and regions this has not materialized. The data used in some of these models and their assumptions may require careful scrutiny. The international institute of forecasters mentions that forecasting of COVID-19 has failed. ${ }^{2}$ Commentators on television started calling for stricter and stricter lockdowns. In South Asia and many parts of the world there is no social security. Many of us live a precarious day-to-day existence. The closing down of economic activity forced many into starvation. The approach of countries varied. Some went into total hibernation while others adopted a more pragmatic approach. In huge countries like India the approach varied from state to state.

Activities we once took for granted like attending crowded sporting events, and concerts are unthinkable at the present time. Cinemas are slowly reopening in many parts with strict social distancing protocols. In most parts of the world people have to wear masks in public places. Sanitizers and disinfectants are an essential part of daily life. We have become afraid of another human being. 
Rather than seeing a person as a friend or companion people are increasingly being seen as sources of infection. Our existing socioeconomic divides have been highlighted. Poorer communities have been hit harder by the pandemic. Racial and ethnic disparities have been highlighted by the pandemic. ${ }^{3}$ In South Asia people living in slums and in substandard housing have seen disproportionately higher infections. Wearing a mask most of the time is difficult and uncomfortable. Wearing personal protective equipment in hot climates like ours is difficult.

Schools and colleges: Schools and colleges shut down early in the pandemic. In some parts of the world they have partially reopened. Learning shifted online. The experience with online learning has been mixed. The major benefit is that it has allowed 'some' learning to continue during the pandemic. Some institutions and countries were better prepared to offer online learning than others. Most medical schools also shifted to online learning. The major challenge has been providing patient exposure. There has also been a shift towards tele-consultations for various medical conditions. Assessment is another huge problem. Many students do not have a quiet place to study at home and many do not have devices to access online learning. Luckily the rapid spread of smart phones in South Asia has provided most students a device for online learning. Bandwidth and connectivity have also improved recently. However, some of the online platforms with video learning facilities requires a high bandwidth.

Failures and profiteering: There have been a degree of failure of international organizations which were supposed to protect us against the pandemic and keep us healthy. Many countries and provinces have been accused of 'dressing up' the data to make the situation look rosier. Making decisions based on incorrect data is dangerous. Scientists in some countries have seen a steady erosion of freedom with the requirement to take permission from authorities before they can publish anything dealing with the pandemic. Many private hospitals have taken advantage of the situation and started charging large fees for COVID-19 treatment. The recent retraction of adverse clinical trial reports with regard to hydroxychloroquine and chloroquine from prestigious medical journals underlines a pursuit of profit. A letter mentions that the retraction of articles related to COVID-19 may be a side effect of the hot publication race. ${ }^{4}$ Editors of the Lancet and the New England Journal of Medicine have been 'persuaded' to publish negative studies about hydroxychloroquine and chloroquine by the pharmaceutical industry according to a recent report. 5 These are cheap drugs unlikely to generate much profit and so unlikely to be promoted.

Contact tracing apps and quarantine: Many contact tracing apps have been developed by different countries. These differ in the amount of personal information collected but all require you to part with a certain amount of personal information. The issue of data privacy and data protection has come to the forefront in some countries. Today as travel is slowly reopening the requirement for quarantine is a dampener. The days of quarantine, the place where you will be quarantined (at home or in an institution), the facilities available during quarantine all vary. The pandemic has led to a loss of personal freedom which was gained painfully through a long struggle during the last two hundred years. 
Tourism, travel and hospitality industry: One of the major industries in recent times has been travel and tourism. People were traveling more than ever before and the money from tourism was slowly changing the lives of people globally. COVID-19 has severely affected this industry and many people may slip back into poverty. One of the major problems is that shutdowns and lower economic activity may push millions of people back into poverty and nullify the significant economic gains of the last three decades. Global poverty could increase for the first time since 1990 and could impact approximately a decade of progress in poverty reduction. ${ }^{6}$ This can also affect political stability and increase the risk of conflict.

Information overload and paucity: The pandemic has highlighted the information overload which characterizes the present era. There are still significant gaps in our knowledge of the virus and the disease. On certain aspects however, there is a lot of information. Some of these are contradictory. The information is constantly evolving and often is confusing. Many articles have been deposited on preprint servers and many journals have a fast track review process for COVID-19 articles. The recent retractions of high-profile papers have added to the confusion.

COVID-19 has affected every facet of global life. Will this be the 'new normal'? I hope not. Being masked and gowned and staying at least one foot from another human being is a poor-quality existence. I hope we are able to control this pandemic soon. I would like to go back to a world where I am free to travel, free to carry out economic activities, free to learn with others in a shared physical space, free to have a cup of coffee with a friend and free from the confusion and fear which this pandemic has generated!

\section{REFERENCES}

1. Coronavirus resource center, Johns Hopkins university of Medicine. COVID-19 dashboard. Available at https://coronavirus.jhu.edu/map.html. Accessed 23 Aug 2020.

2. Ioannidis JPA, Cripps S, Tanner MA. Forecasting for COVID-19 has failed - International Institute of Forecasters. Available at http://adam.curry.com/art/1592232069_rp2H VXpm.html. Accessed 23 Aug 2020.

3. Webb Hooper M, Nápoles AM, Pérez-Stable EJ. COVID-19 and Racial/Ethnic Disparities. JAMA. 2020 May 11. doi: 10.1001/jama.2020.8598.

4. Soltani, P., Patini, R. Retracted COVID-19 articles: a side-effect of the hot race to publication. Scientometrics 2020. https://doi.org/10.1007/s11192-020-03661-9

5. Patriot Daily News. Bombshell: Leaked conversations of Lancet and NEJM editors-inchief reveals they already know big pharma is a "criminal" cartel pushing rigged science for profit. Available from: https://patriotdailypress.com/2020/06/10/bo mbshell-leaked-conversation-of-lancet-andnejm-editors-in-chief-reveals-they-alreadyknow-big-pharma-is-a-criminal-cartel-pushingrigged-science-for-profit/. Accessed 23 Aug 2020.

6. WIDER working paper 2020/43. Sumner A, Hoy C, Ortiz-Juarez E. Estimatess of the impact of COVID-19 on global poverty. Available from: https://www.wider.unu.edu/sites/default/files /Publications/Working-paper/PDF/wp202043.pdf. Accessed 23 Aug 2020.

\section{Correspondence to:}

Dr P Ravi Shankar International Medical University No 126, Jalan Jalil Perkasa 19

Bukit Jalil, Kuala Lumpur 57000 Malaysia

Phone: +603 86567228

E-mail: ravi.dr.shankar@gmail.com 